九州大学学術情報リポジトリ

Kyushu University Institutional Repository

\title{
Green Synthesis Silver Nanoparticles (AgNPs) Using Lamtoro Pods Extract (Leucaena Leucocephala) and Their Potential for Mercury Ion Detection
}

Muhamad Allan Serunting

Department of Chemistry, Institut Teknologi Sumatera

Okky Fajar Tri Maryana

Department of Physics, Institut Teknologi Sumatera

Erga Syafitri

Department of Pharmacy, Institut Teknologi Sumatera

Solina Balqis

Department of Chemistry, Institut Teknologi Bandung

他

https://doi.org/10.5109/4372261

出版情報: Evergreen. 8 (1)，pp.63-68，2021-03. Transdisciplinary Research and Education Center for Green Technologies, Kyushu University バージョン :

権利関係 : 


\title{
Green Synthesis Silver Nanoparticles (AgNPs) Using Lamtoro Pods Extract (Leucaena leucocephala) and Their Potential for Mercury Ion Detection
}

\author{
Muhamad Allan Serunting ${ }^{* 1}$ Okky Fajar Tri Maryana ${ }^{2}$, \\ Erga Syafitri ${ }^{3}$, Solina Balqis ${ }^{4}$, Elsa Windiastuti ${ }^{5}$ \\ ${ }^{1}$ Department of Chemistry, Institut Teknologi Sumatera, Indonesia \\ ${ }^{2}$ Department of Physics, Institut Teknologi Sumatera, Indonesia \\ ${ }^{3}$ Department of Pharmacy, Institut Teknologi Sumatera, Indonesia \\ ${ }^{4}$ Department of Chemistry, Institut Teknologi Bandung, Indonesia \\ ${ }^{5}$ Department of Agro-Industrial Technology, Institut Teknologi Sumatera, Indonesia \\ *Author to whom correspondence should be addressed, \\ *Email: muhamad.serunting@ki.itera.ac.id
}

(Received August 26, 2020; Revised December 18, 2020; accepted January 23, 2021).

\begin{abstract}
Synthesis of silver nanoparticles, as potential mercury metal detection, using Lamtoro Pods extracts has been successfully carried out by the green reduction method. The peak spectrum of plasmon resonance (SPR) at $415 \mathrm{~nm}$ confirmed the formation of silver nanoparticles. The Fourier transform infrared (FTIR) test obtained a characteristic functional group vibration spectrum in Lamtoro Pods. A shift of wavenumber was distinguished by comparing the FTIR spectrum between Lamtoro pods extract and silver nanoparticles. This indicated the involvement of phenol and flavonoid compounds found in the Lamtoro act as a reducing agent of $\mathrm{Ag}^{+}$to $\mathrm{Ag}^{0}$ (silver nanoparticles). The X-ray diffractometer (XRD) pattern showed that the material synthesized as silver nanoparticles. The transmission electron microscopy (TEM) characterization showed that the nanoparticles have an average size $15.70 \mathrm{~nm}$. The color intensity of silver nanoparticles decreased to be colorless after being contacted with mercury ion, indicating its potential for mercury metal ions detection.
\end{abstract}

Keywords: Silver Nanoparticles; Green Synthesis; Monitoring of Mercury

\section{Introduction}

Recently, nanomaterials have become a major interest for many researchers. Nanomaterials have been used in wide applications in various fields because of their size, shape, and composition associated with their chemical, physical and optical properties. For instance, nanomaterials have been widely applied in human life, such as medicine, chemistry, and technology ${ }^{122}$. The synthesis of silver nanoparticles is generally carried out through the thermal decomposition method, electrochemistry approach, or microwave-assisted method ${ }^{3-5)}$. Economically, those methods are quite expensive because they require high energy, use hazardous chemical compounds, and produce toxic waste to humans. Therefore, they are not under the Green Chemistry principle, aiming to design chemical synthesis products by minimizing toxic waste by-products. The green chemistry approach can reduce environmental degradation effects with green culture and green lifestyle in science society ${ }^{6}$.
Currently, the biosynthesis method, which employs plant extracts as reducing and stabilizer agents, has been developed as an alternative method to synthesize silver nanoparticles without using toxic chemical compounds. This method has several advantages, such as relatively low cost, easy to process and purification, and classified as green synthesis. Various plant extracts were reported as reducing agents to synthesize silver nanoparticles such as dragon fruit peel ${ }^{7)}$, pomegranate skin ${ }^{8)}$, jicama ${ }^{9)}$, salvia Spinosa ${ }^{10)}$, and so forth.

Lamtoro (Leucaena leucocephala) is a shrub or evergreen tree. It can grow to $7-20 \mathrm{~m}$ tall with bipinnate leaf anatomy, 4-7 pairs of pinnae less than 4-10 cm long, each with 10 to 20 pairs of Lanceolate leaflets. Lanceolate leaves are less than $45 \mathrm{~mm}$ long. The flowers are white, with a round head about $2 \mathrm{~cm}$ in diameter. The pods are flat with a length of $10-15 \mathrm{~cm}^{11)}$. Lamtoro is a local plant in Indonesia whose fruit is currently used as additional food. The Lamtoro pods become household waste and can be processed to have benefits. 
Mercury has a density of $13,546 \mathrm{gm} \mathrm{cm}^{-3}$, which is classified as a group of heavy metal. This heavy metal is one of the most toxic elements for human health when exposed directly or enters the human body through environmental pollution. The mercury $\mathrm{Hg}^{2+}$ metal ions are the most stable and widespread pollutants. According to the WHO Guidelines for Drinking-water Quality, mercury levels may not exceed $0.001 \mathrm{ppm}$ in drinking water ${ }^{12)}$. Mercury and other heavy metal can release into the water environment by human activity such as the mining industry ${ }^{13)}$. Methods, such as desalination ${ }^{14)}$, membrane ${ }^{15)}$, and bioremediation technology for sustainable wastewater treatment 16), have been developed by researchers to obtain clean water. Other researchers also focus on wastewater monitoring, especially detecting mercury levels in the water, which is vital for daily life.

The methods commonly used to detect the presence of mercury with accuracy and precision are atomic absorption spectrometry (AAS) ${ }^{17)}$, electrochemical analysis ${ }^{18)}$, cold vapor atomic fluorescence spectrometry 19), and inductively coupled plasma mass spectrometry (ICP-MS) ${ }^{20)}$. Unfortunately, these methods require expensive equipment, expensive maintenance, elaborate sample preparation, and difficult to be applied in the analytical field. This research detects mercury metal ions using a simple, facile, and inexpensive colorimetric method, utilizing the redox reaction between mercury metal ions and silver nanoparticles. This method measures the compound color concentration by determining the specific wavelength absorbance value using a spectrophotometer ${ }^{21)}$. Nowadays, silver and gold nanoparticles have been used widely in colorimetric analysis for biosensors of many substances (such as viruses, cancer cells, toxic substances, pesticides, heavy metals, inorganic and organic pollutants in water) ${ }^{22)}$.

In this research, Lamtoro pods waste was utilized as a reducing agent in the synthesis of silver nanoparticles. Exploring the use of Lamtoro pods as reducing agents in synthesizing silver nanoparticles has never been reported before.

\section{Materials and methods}

\subsection{Materials}

All reagents were analytical grade and used directly without any further purification. The reagents were $\mathrm{AgNO}_{3}, \mathrm{HgCl}_{2}$ purchased from Merck Indonesia. The $1000 \mathrm{ppm}$ of $\mathrm{Pb}$ (II) solution was prepared from $\mathrm{HgCl}_{2}$ salt dissolved in distilled water.

\subsection{Method of qualitative analysis}

The characterization of Silver Nanoparticles (AgNPs) was carried out by using UV-Vis spectrophotometer (Agilent Spectrophotometer Cary 50, America) using a quartz cuvette. The Fourier Transform Infrared (FTIR) (Agilent FTIR Cary 630, America) instrument was used to record the functional group vibration in material, operated at $1 \mathrm{~cm}^{-1}$ in resolution using $\mathrm{KBr}$ plate, and range $650-4000 \mathrm{~cm}^{-1}$. Transmission Electron Microscopy (TEM) (Hitachi H-7100, Japan) instrument was carried out to obtain the nanoparticles size and structure observed in $120 \mathrm{kV}$ and zooming 150K-200Kx. X-ray Diffractometer (XRD) (Rigaku Smartlab, Japan) instrument was carried out to determine the nanoparticles crystal structure. The software ImageJ 1.46r was used to process the average particle size data from TEM images.

\subsection{Synthesis of silver nanoparticles (AgNPs)}

The Lamtoro pods extract was freshly prepared by removing impurities, cutting into small pieces, and drying at room temperature. Afterward, it was mashed using a blender to be a fine Lamtoro pods powder. 10 grams of powder boiled in $100 \mathrm{~mL}$ of distilled water at $80^{\circ} \mathrm{C}$ for 15 minutes to get the extracts. The extract was filtered through Whatman paper. The filtrate was stored in a refrigerator at $4{ }^{\circ} \mathrm{C}$ for further use.

$\mathrm{AgNO}_{3} 1 \mathrm{mM}$ solution was prepared from a $10 \mathrm{mM}$ stock solution. $10 \mathrm{~mL}$ of $\mathrm{AgNO}_{3}$ solution was put into the chemical glass $25 \mathrm{~mL}$. It was then slowly dropped the Lamtoro pods extract with various volumes $(0.1 ; 0.5 ; 1$ and $2 \mathrm{~mL}$ ). The mixture was shaken by hands and let stand for 15 minutes in sunlight radiation until the color was observed changes.

The AgNPs solution was centrifuged at $4500 \mathrm{rpm}$, then dried in the oven at $80{ }^{\circ} \mathrm{C}$ to obtain silver nanoparticle powder. Then the AgNPs powder was further characterized.

\subsection{Colorimetry detection of $\mathrm{Hg}$ (II) ions using silver nanoparticles solution}

$\mathrm{Hg}$ (II) ion solutions of various concentrations were prepared from stock solutions. $3 \mathrm{~mL}$ of silver nanoparticles (AgNPs) solution was added into each variation of the $\mathrm{Hg}$ (II) ions concentration while shaken by hand. The change of solution color was determined using a UV-Vis spectrophotometer.

\section{Results and discussion}

\subsection{Synthesis of silver nanoparticles (AgNPs)}
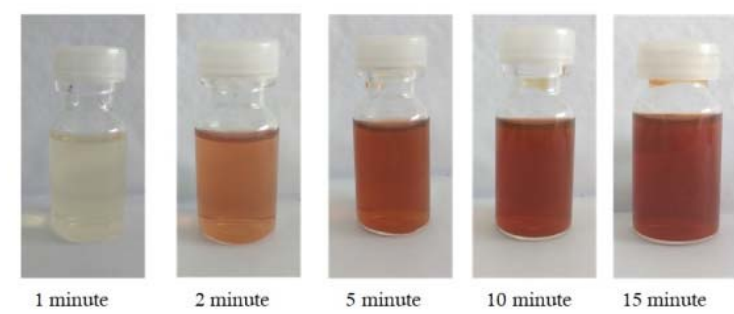

Fig. 1: The color change of $\mathrm{AgNO}_{3}$ solution after adding Lamtoro pods extract

The synthesis of silver nanoparticles was done by slowly adding Lamtoro pods extract into $1 \mathrm{mM}$ silver 
nitrate $\left(\mathrm{AgNO}_{3}\right)$ solution. The synthesis process was carried out under sunlight irradiation for 15 minutes to elevate the reaction rate. The nanoparticles solution was characterized by a change in the silver nitrate solution color from colorless to reddish-brown. Over time the reddish-brown color was getting thicker. It showed that the synthesis process with the bottom-up method has occurred. Over time, the reddish-brown color becomes more intense, as shown in Fig. 1.

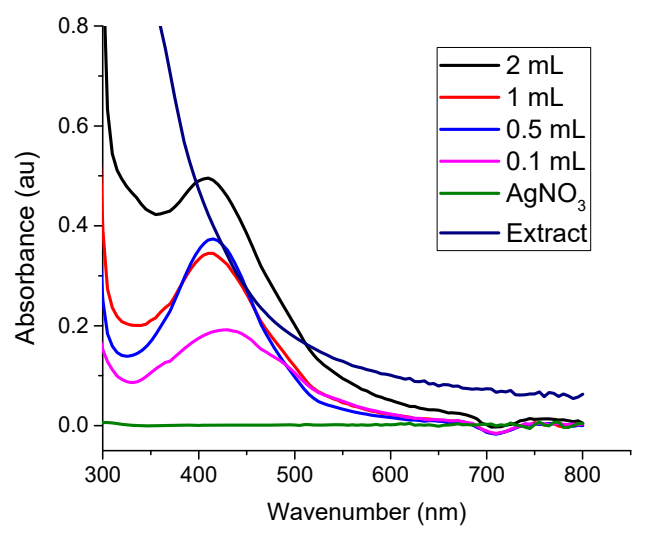

Fig. 2: The absorption spectrum of silver nanoparticles (AgNPs)

Fig. 2 shows the plasmon resonance spectrum (SPR) of silver nanoparticles. It can be seen that the maximum absorbance value was elevated by increasing the Lamtoro pods extract volume. This indicates that the more extract used in this research, the more species that act as reducing agents to produce nanoparticles. The SPR peak at $415 \mathrm{~nm}$ confirms the formation of silver nanoparticles.

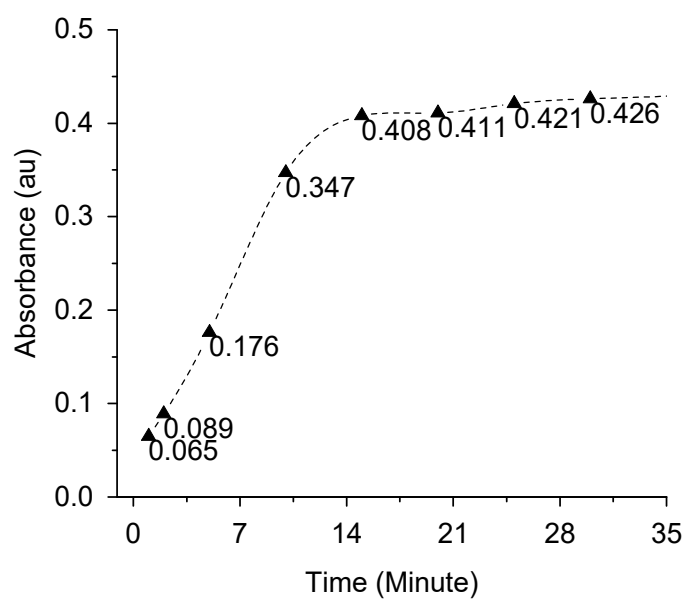

Fig. 3: Effect of time on absorbance value at $415 \mathrm{~nm}$.

Fig 3 shows that silver nanoparticles formation increased over time, revealed by an increase in absorption value. Green synthesis of silver nanoparticles under optimal sunlight radiation for 15 minutes has been performed. This result was much better than previous research conducted by Lutfi et al., synthesizing silver nanoparticles without treatment under sunlight requires an optimum time of 7 days ${ }^{9}$ ).

\subsection{Characterization of silver nanoparticles (AgNPs)}

\section{FTIR analysis}

Fig 4 depicts a functional group vibrational spectrum in a sample of Lamtoro pods extract, showing a typical vibration at a wavenumber of $3257.7 \mathrm{~cm}^{-1}$ correspondings to a hydroxyl group $(\mathrm{O}-\mathrm{H})$, which is likely to originate from alcohol and phenol. Wavenumbers at $1610.2 \mathrm{~cm}^{-1}$ and $1437.3 \mathrm{~cm}^{-1}$ are typical vibrations of the $\mathrm{C}=\mathrm{O}$ asymmetry and $\mathrm{C}=\mathrm{O}$ symmetry functional groups found in Lamtoro pods extracts. A peak at $1028.7 \mathrm{~cm}^{-1}$ is vibrational of the $\mathrm{C}-\mathrm{OH}$ functional group. A shift in wavenumber was observed by comparing the FTIR spectrum of Lamtoro pods extract and silver nanoparticles. This indicates the involvement of phenol, ascorbic acid, and flavonoid compounds found in the Lamtoro pods used as a reducing agent of $\mathrm{Ag}^{+}$to $\mathrm{Ag}^{0}$ (silver nanoparticles) ${ }^{23,24)}$.

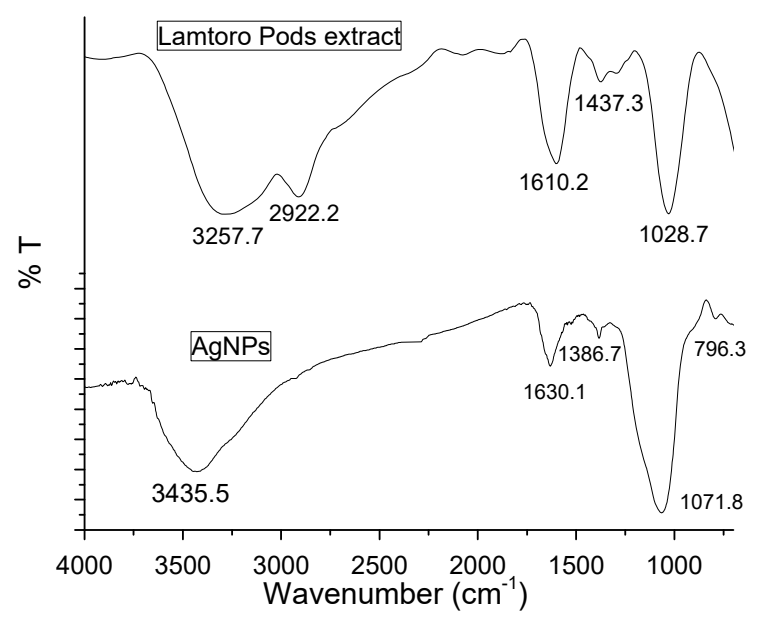

Fig. 4: FTIR Spectrum for Lamtoro pods extract and silver nanoparticles.

\section{XRD analysis}

A diffractogram of silver nanoparticles is shown in Fig 5. The peaks were in accordance with JCPDS No. 01-1167. The crystal of silver nanoparticles was confirmed by X-ray diffraction (XRD) patterns. The diffractogram pattern shown in Fig $\mathbf{5}$ revealed the silver nanoparticle crystal. 


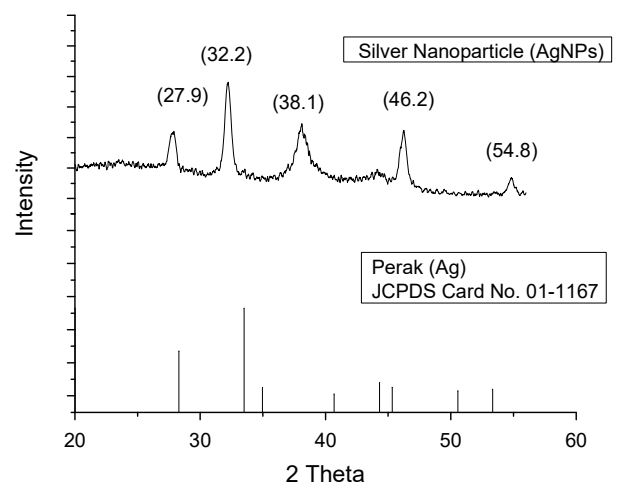

Fig. 5: Diffraction pattern of silver nanoparticle (AgNPs)
The Crystal size can be calculated using the Debye Scherrer equation. The following are Debye Scherrer's equations:

$$
D=\frac{K \lambda}{\beta \cos \theta}
$$

where $\mathrm{k}$ is Scherrer constant $(0.89), \beta$ the peak width of half-maximum (FWHM), $\lambda$ the X-ray wavelength $(0.15405 \mathrm{~nm})$, and $\theta$ is the Bragg diffraction angle. The average crystal size is $15.25 \mathrm{~nm}$, which is not much different from the transmission electron microscopy measurement results.
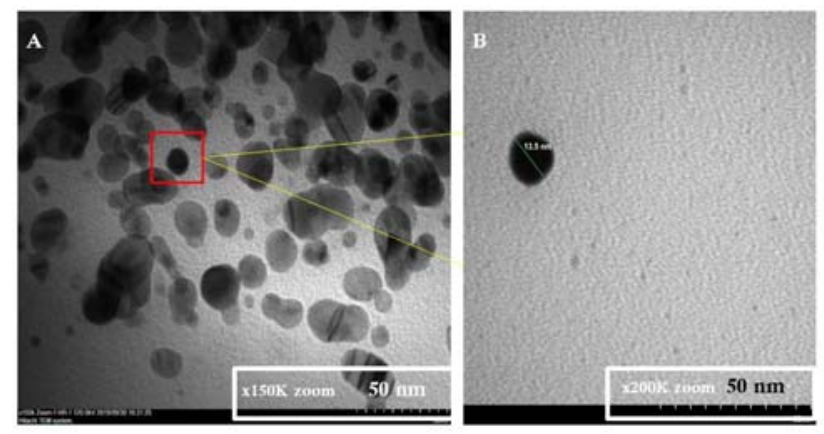

Fig. 6: TEM image analysis of silver nanoparticles in (a) $150 \mathrm{Kx}$ and (b) $200 \mathrm{Kx}$
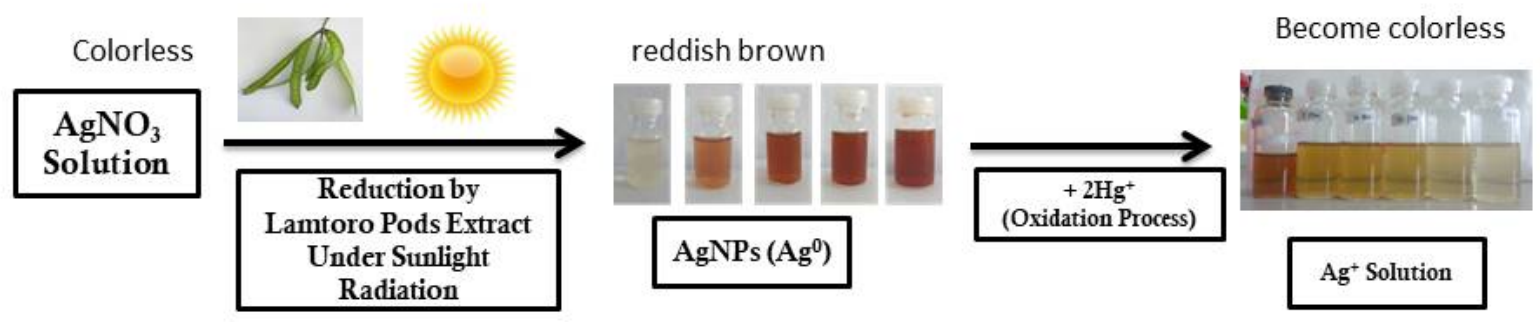

Fig. 7: The synthesis illustration of AgNPs using Lamtoro Pods extract and redox reaction of $\mathrm{Hg}$ (II) colorimetric

\section{TEM analysis}

The transmission electron microscopic (TEM) image from Fig. 6 shows the morphology and size of the silver nanoparticles. The size of spherical silver nanoparticles showed from the TEM image was calculated by using ImageJ software, which was found around $15.70 \mathrm{~nm}$. This result was in good agreement with the XRD diffractogram data. The spherical shape has been reported in many previous studies using another reduction agent include extracts of pumpkin ${ }^{25}$, Reetha and Shikakai ${ }^{26)}$, and Azadirachta indica leaf extract ${ }^{27)}$. The nanosize makes AgNPs have many benefits in many fields. Such as antimicrobial activities, catalysis, plasmonics, optoelectronics, DNA sequencing, contamination monitoring and climate change, water purification technology, energy generation, information storage, biomedical and biological applications ${ }^{28,29)}$.
The potential of silver nanoparticles to detect mercury metal ions.

Fig 7 reveals an illustration synthesis of AgNPS and its potential for $\mathrm{Hg}$ (II) detection. The reaction potential cell is positive, indicating a spontaneous reaction due to the negative value of Gibbs free energy. The presence of $\mathrm{Hg}$ (II) ions in a solution of silver nanoparticles (AgNPs) will oxidize $\mathrm{Ag}^{0}$ to $\mathrm{Ag}^{+}$, which is marked by a decrease in color intensity to be more clear ${ }^{9}$. The absorbance value of Surface Plasmon Resonance (SPR) decreases with increasing $\mathrm{Hg}$ ions concentration added to the silver nanoparticle solution (AgNPs) shown in Fig 8. The calibration curve of silver nanoparticles (AgNPs) solution after incorporating $\mathrm{Hg}$ (II) ion with various concentrations showed the correlation coefficient $\left(r^{2}\right)=$ 0.9917. It indicated that silver nanoparticles have the potential to be a colorimetric method of determining $\mathrm{Hg}$ 
ion levels in solutions with redox reactions:

$$
\begin{aligned}
& 2 \mathrm{Hg}^{2+}+2 \mathrm{e}^{-} \rightarrow \mathrm{Hg}_{2}{ }^{2+} \quad \mathrm{E}^{0}=+0.92 \mathrm{~V} \\
& \mathrm{Ag}^{+}+\mathrm{e}^{-} \rightarrow \mathrm{Ag} \quad \mathrm{E}^{0}=+0.80 \mathrm{~V} \\
& \text { Reduction: } 2 \mathrm{Hg}^{2+}+2 \mathrm{e} \rightarrow \mathrm{Hg}_{2}{ }^{2+} \quad \mathrm{E}^{0}=+0.92 \mathrm{~V} \\
& \text { Oxidation: } 2 \mathrm{Ag} \rightarrow 2 \mathrm{Ag}^{+}+2 \mathrm{e}^{-} \quad \mathrm{E}^{0}=-0.80 \mathrm{~V} \\
& \text { Overall: } 2 \mathrm{Hg}^{2+}+2 \mathrm{Ag} \rightarrow \mathrm{Hg}_{2}{ }^{2+}+2 \mathrm{Ag}^{+} \quad \mathrm{E}^{0} \text { sel }=+0,12 \mathrm{~V}
\end{aligned}
$$
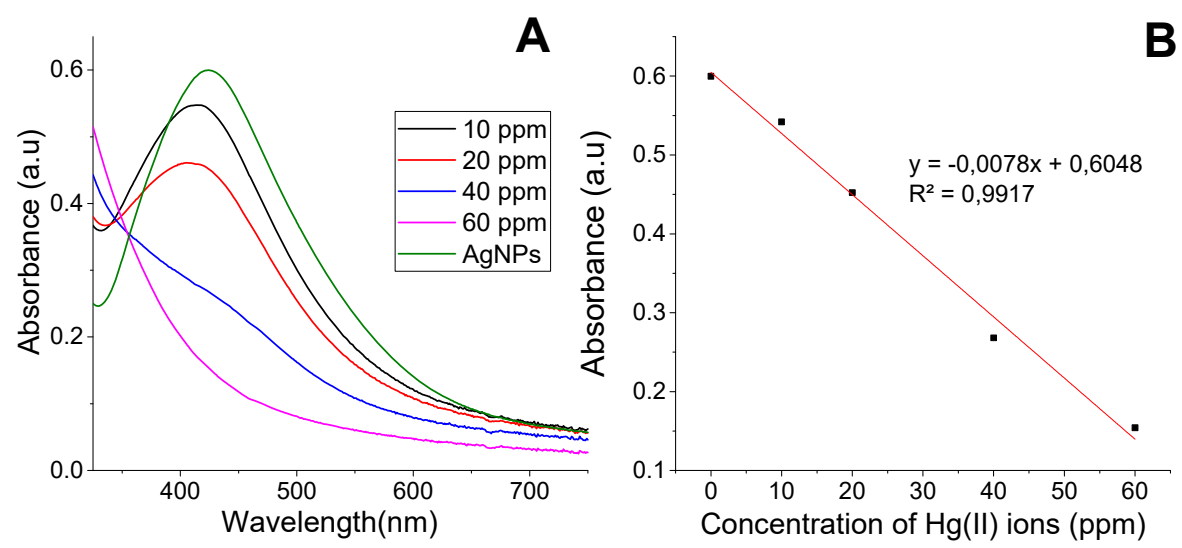

Fig. 8: UV- Visible spectra of AgNPs. a) After the addition of various concentrations of $\mathrm{Hg}(\mathrm{II})$ ions.

b) Calibration curve of AgNPs after re-oxidation by various concentration of $\mathrm{Hg}$ (II) ions

\section{Conclusion}

Green synthesis of silver nanoparticles with an inexpensive and efficient potential to detect mercury metal ions has been successfully reported. The optimal treatment of this green synthesis was under the sunlight for 15 minutes. The compounds such as phenols, flavonoids, and vitamin $\mathrm{C}$ contained in the Lamtoro pods extract act as a green reductor to form silver nanoparticles. The silver nanoparticles have the potential to be a method of determining $\mathrm{Hg}$ ion levels in solutions. It confirms from the calibration curve of silver nanoparticles (AgNPs) solution after the presence of $\mathrm{Hg}$ (II) ion with various concentrations showed the correlation coefficient $\left(\mathrm{r}^{2}\right)=0.9917$.

\section{Acknowledgment}

This experiment was supported by HIBAH SMART FRIENDLY INSTITUT TEKNOLOGI SUMATERA 2019 (contract number: B/298/IT9.C1/PT.01.03/2019).

\section{References}

1) S.H. Lee, and B.H. Jun, "Silver nanoparticles: synthesis and application for nanomedicine," Int. J. Mol. Sci., 20 (4) (2019). doi:10.3390/ijms20040865.

2) M.A. Serunting, R. Rusnadi, D.A. Setyorini, and B.S.
Ramadan, "An effective cerium (iii) ions removal method using sodium alginate-coated magnetite (alg-fe3o4) nanoparticles," J. Water Supply Res. Technol., $\quad 67 \quad$ (8) $\quad 754-765 \quad$ (2018). doi:10.2166/aqua.2018.086.

3) M. Nakano, T. Fujiwara, and N. Koga, "Thermal decomposition of silver acetate: physico-geometrical kinetic features and formation of silver nanoparticles," J. Phys. Chem. C, 120 (16) 88418854 (2016). doi:10.1021/acs.jpcc.6b02377.

4) M. Starowicz, B. Stypuła, and J. Banaś, "Electrochemical synthesis of silver nanoparticles," Electrochem. Commun., 8 (2) 227-230 (2006). doi:10.1016/j.elecom.2005.11.018.

5) M. Parveen, F. Ahmad, A.M. Malla, and S. Azaz, "Microwave-assisted green synthesis of silver nanoparticles from fraxinus excelsior leaf extract and its antioxidant assay," Appl. Nanosci., 6 (2) 267-276 (2016). doi:10.1007/s13204-015-0433-7.

6) B. Shahriari, A. Hassanpoor, A. Navehebrahim, and S. Jafarinia, "A systematic review of green human resource management a systematic review of green human resource management," Evergreen, 6 (2) 177-189 (2019).

7) S. Phongtongpasuk, S. Poadang, and N. Yongvanich, "Environmental-friendly method for synthesis of silver nanoparticles from dragon fruit peel extract and their antibacterial activities," Energy Procedia, 
89

$239-247$

(2016).

doi:10.1016/j.egypro.2016.05.031.

8) M. Shanmugavadivu, S. Kuppusamy, and R. Ranjithkumar, "Synthesis of pomegranate peel extract mediated silver nanoparticles and its antibacterial activity," Am. J. Adv. Drug Deliv., 2 (2) 174-182 (2014).

9) F.M. Lutfi, M. Juwita, P.R. Ibrahim, E.D. Rakhmawaty, and R. Iman, "Biosynthesis of silver nanoparticles using jicama extract and its application for colorimetric sensing of mercury ions," Res. J. Chem. Environ., 22 (Special issue II) 1-3 (2018).

10) S. Pirtarighat, M. Ghannadnia, and S. Baghshahi, "Green synthesis of silver nanoparticles using the plant extract of salvia spinosa grown in vitro and their antibacterial activity assessment," $J$. Nanostructure Chem., $9 \quad$ (1) 1-9 (2019). doi:10.1007/s40097-018-0291-4.

11) T.M. El-Lamey, "Morphological and anatomical responses of leucaena leucocephala (lam.) de wit. and prosopis chilensis (molina) stuntz to rassudr conditions," J. Appl. Environ. Biol. ..., 5 (7) 43-51 (2015).

12) M. Kumar, and A. Puri, "A review of permissible limits of drinking water," Indian J. Occup. Environ. Med., $\quad 16 \quad$ (1) 40-44 (2012). doi:10.4103/0019-5278.99696.

13) S. Dwiki, "Development of environmental policy in indonesia regarding mining industry in comparison with the united states and australia: the lesson that can be learned," Evergreen, 5 (2) 50-57 (2018). doi:10.5109/1936217.

14) M.W. Shahzad, K. Thu, B.B. Saha, and K.C. Ng, "An emerging hybrid multi-effect adsorption desalination system," Evergreen, 1 (2) 30-36 (2014). doi: $10.5109 / 1495161$.

15) B.T. Sabarudin, and S. Kartohardjono, "The combination of coagulation-flocculation and membrane processes to minimize pollution of tofu wastewater," Evergreen, 7 (1) 56-60 (2020). doi:10.5109/2740942.

16) S. Kitjanukit, "Attitude toward bioremediation-related technology and relation with company social responsibility," Evergreen, 6 (3) 240-245 (2019). doi:10.5109/2349300.

17) E. Bulska, W. Kandler, P. Pasławski, and A. Hulanicki, "Atomic absorption spectrometric determination of mercury in soil standard reference material following microwave sample pretreatment," Mikrochim. Acta, 119 (1-2) 137-146 (1995). doi:10.1007/BF01244862.

18) D. Martín-Yerga, M.B. González-García, and A. Costa-García, "Electrochemical determination of mercury: a review," Talanta, 116 1091-1104 (2013). doi:10.1016/j.talanta.2013.07.056.

19) P. Cava-Montesinos, E. Ródenas-Torralba, Á. Morales-Rubio, M.L. Cervera, and M. De La
Guardia, "Cold vapour atomic fluorescence determination of mercury in milk by slurry sampling using multicommutation," Anal. Chim. Acta, 506 (2) 145-153 (2004). doi:10.1016/j.aca.2003.11.023.

20) G. Ho Lee, G.-J. Kang, J.Y. Kim, R.E. Russo, M.Y. Lee, J.Y. Yang, K. Su Kim, S.H. Choi, J.H. Yoo, E. Mi Choi, J.-S. Yang, and K. Su Park, "Heavy metal determination by inductively coupled plasma - mass spectrometry (icp-ms) and direct mercury analysis (dma) and arsenic mapping by femtosecond (fs) laser ablation (la) icp-ms in cereals," Anal. Lett., 52 (3) 1-13 (2019). doi:10.1080/00032719.2018.1471484.

21) O. Gapurova, R.R. Khaydarov, R.A. Khaydarov, I. Garipov, and M. Lutfi Firdaus, "Silver nanoparticles as a biocide for water treatment applications," 407419 (2019). doi:10.1007/978-3-030-02381-2_18.

22) S. Maiti, G. Barman, and J. Konar Laha, "Detection of heavy metals $(\mathrm{cu}+2, \mathrm{hg}+2)$ by biosynthesized silver nanoparticles," Appl. Nanosci., 6 (4) 529-538 (2016). doi:10.1007/s13204-015-0452-4.

23) P. Kousalya, and V. Jayanthy, "Evaluation of phytochemicals and quantification of phenol, flavonoids and tannins of pods of leucaena leucocephala ( lam .) de wit," 16 (9) 1561-1564 (2016). doi:10.5829/idosi.aejaes.2016.1561.1564.

24) J.A. Duke, "Handbook of legumes of world economic importance," 1st Editio, Plenum Press, New York, 1981. doi:10.1007/978-1-4684-8151-8.

25) R.I. Iyer, and T. Panda, “ Biosynthesis of gold and silver nanoparticles using extracts of callus cultures of pumpkin ( cucurbita maxima )," J. Nanosci. Nanotechnol., $18 \quad$ (8) 5341-5353 (2018). doi:10.1166/jnn.2018.15378.

26) U. Kumar Sur, B. Ankamwar, S. Karmakar, A. Halder, and P. Das, "Green synthesis of silver nanoparticles using the plant extract of shikakai and reetha," Mater. Today Proc., 5 (1) 2321-2329 (2018). doi:10.1016/j.matpr.2017.09.236.

27) S. Ahmed, Saifullah, M. Ahmad, B.L. Swami, and S. Ikram, " Green synthesis of silver nanoparticles using azadirachta indica aqueous leaf extract ," $J$. Radiat. Res. Appl. Sci., 9 (1) 1-7 (2016). doi:10.1016/j.jrras.2015.06.006.

28) M. Rafique, I. Sadaf, M.S. Rafique, and M.B. Tahir, "A review on green synthesis of silver nanoparticles and their applications," Artif. Cells, Nanomedicine Biotechnol., $45 \quad$ (7) 1272-1291 (2017). doi:10.1080/21691401.2016.1241792.

29) A. Syafiuddin, Salmiati, M.R. Salim, A. Beng Hong Kueh, T. Hadibarata, and H. Nur, "A review of silver nanoparticles: research trends, global consumption, synthesis, properties, and future challenges," $J$. Chinese Chem. Soc., 64 (7) 732-756 (2017). doi:10.1002/jccs.201700067. 